\title{
Awareness of cytomegalovirus and risk factors for susceptibility among pregnant women, in Montreal, Canada
}

\author{
Sarah Wizman ${ }^{1,5^{*}}$ (D), Valérie Lamarre ${ }^{1}$, Lena Coic ${ }^{1}$, Fatima Kakkar ${ }^{1}$, Jean-Baptiste Le Meur ${ }^{2}$, Céline Rousseau ${ }^{1,3}$, \\ Marc Boucher ${ }^{4}$ and Bruce Tapiero ${ }^{1}$
}

\begin{abstract}
Background: Advances in diagnostic and therapeutic modalities for congenital cytomegalovirus (CMV) infection have generated a mounting interest in identifying mothers susceptible to CMV. The objectives of this study were to evaluate the prevalence and socio-demographic determinants of CMV susceptibility and CMV awareness, among pregnant women, in Montreal, Quebec.

Methods: Between April and December 2012, women delivering at Centre Hospitalier Universitaire Sainte Justine were recruited for the study. Stored serum from the first trimester of pregnancy was tested for CMV IgG. Knowledge about CMV and socio-demographic characteristics were collected via standardized questionnaire.

Results: Four hundred and ninety one women were enrolled in the study. Overall, 225 mothers (46\%) were seronegative for CMV, and $85 \%(n=415)$ were unaware of CMV or the associated risks in pregnancy. Significant risk factors for CMV seronegative status included Canadian vs. foreign born (aOR 6.88, $95 \% \mathrm{Cl} 4.33-10.94$ ), and high vs. low family income (aOR 4.68, $95 \% \mathrm{Cl}$ 2.09-10.48). Maternal employment status was the only significant predictor of CMV unawareness, with unemployed mothers at the highest risk (aOR 85.6, $95 \% \mathrm{Cl} 17.3-421.3$ ).

Conclusions: Nearly half of pregnant women studied were at risk of primary infection, and yet, the majority was unaware of potential risks associated with CMV. Canadian born mothers and those with a high socioeconomic status were more likely to be CMV seronegative. Increased education about CMV infection, through public health interventions and obstetrician/pediatric counseling, is needed for all pregnant women.
\end{abstract}

Keywords: Cytomegalovirus, Serostatus, Awareness, Socio-demographic risk factors, Pregnant women

\section{Background}

Cytomegalovirus (CMV) is the most common cause of congenital infection, with an overall birth prevalence in the developed world of $0.64 \%$ [1]. Congenital CMV infection (cCMV) is the leading non-genetic cause of deafness in children [2] and is also responsible for significant developmental delays in infected children, whether symptomatic or not at birth [3]. Overall ensuing societal costs are estimated to be billions of dollars annually $[4,5]$, with at

\footnotetext{
* Correspondence: lydasa@yahoo.com

${ }^{1}$ Infectious Disease Division, Department of Paediatrics, CHU Sainte Justine, Université de Montréal, 3175 Ch. de la Cote-Sainte-Catherine (bureau 7412), Montréal H3T1C5, QC, Canada

${ }^{5} 5632$ Irving Layton, Montréal H4WOA2, QC, Canada

Full list of author information is available at the end of the article
}

least \$14.3 million per year for the hospitalization of symptomatic infants in the United States [6].

Primary maternal CMV infection during pregnancy will result in viral transmission to the fetus in $40 \%$ of cases, whereas $1 \%$ of women already infected before pregnancy (known CMV seropositive) will transmit the virus, either through viral reactivation or reinfection with a different strain [7]. However, the severity of fetal complications is highest with maternal primary infection early in pregnancy $[8,9]$. Therefore, maternal CMV seronegative status constitutes a major risk factor for congenital CMV disease in children.

Although the role of screening for CMV has been intensely debated in the last decade $[10,11]$, there remains no consensus on the need to screen all pregnant women, 
nor on selected populations to target. Recent advances in both diagnostic and therapeutic modalities in managing congenital CMV have also ignited interest in the need for neonatal screening [12-17]. While early treatment may well limit the sequelae of disease in children, prevention remains the cornerstone of efforts to limit the global burden of cCMV disease [18]. Until an effective CMV vaccine becomes available, behavioral interventions may indeed represent the best preventive measure for cCMV. Education on basic hygiene measures to newly pregnant at risk mothers proved to significantly reduce the incidence of maternal infection during pregnancy [19-21]. However, in Canada, there is limited data on which women are actually at risk for primary CMV infection. The first Canadian epidemiologic studies in the 1970s revealed a maternal seronegative status rate of 56-64\% [22-26]. More recent data in selected subgroups showed a lower rate of $43 \%$ in daycare workers in Montreal [27] and of $45 \%$ in mothers of low birth weight infants in Alberta [28]. Given that sociodemographic factors have greatly changed overtime in Canada, with successive immigration waves, smaller family sizes and new child daycare programs, current data on CMV risk in pregnancy are essential to identify targeted groups for public health interventions.

The primary objective of this study was to determine CMV susceptibility and awareness of CMV disease among pregnant women delivering at Centre Hospitalier Universitaire (CHU) Sainte-Justine, in Montreal, Quebec. Secondary objectives were to determine risk factors for CMV susceptibility and lack of CMV awareness.

\section{Methods}

\section{Study population}

All pregnant women delivering at CHU Sainte-Justine between April and December 2012 were eligible for the study. There are approximately 3500 live births annually at this tertiary care mother-child hospital, which represent $15 \%$ of births in the city of Montreal, which itself represents more than a quarter of births of the Province of Quebec [29]. The cost of medical care for all women is provided by the provincial health plan, under a system of universal health care access.

Inclusion criteria for the study were: 1) Availability of stored first trimester blood in the Sainte-Justine laboratory 2) Age older than 18 years and 3) Capacity to provide written consent in French or English. Mothers whose babies were hospitalized in the neonatal intensive care unit were excluded from the study to prevent additional hospitalization stress. Recruitment occurred on the postpartum ward on 80 pre-specified weekdays, based on staffing availability. Members of the research team (SW and LC) and a research assistant approached mothers before their hospital discharge. During the same interview, they obtained patient consent to participate in the study, administered and simultaneously completed the standard questionnaire described below.

The ethics committee of the Sainte-Justine research center approved the study.

\section{Serology}

Maternal CMV IgG antibody levels were measured on stored first trimester routine blood test using the automated enzyme immunoassay analyzer Triturus (Diagnostics Grifols, S.A., Barcelona, Spain). CMV serostatus was defined as negative if a serum titer was $<0.9 \mathrm{U} / \mathrm{mL}$, equivocal between 0.9 and $1.1 \mathrm{U} / \mathrm{mL}$, and positive if $>1.1$ $\mathrm{U} / \mathrm{mL}$. Laboratory results were mailed to the mothers along with an explanatory letter. A pamphlet about preventive measures on $\mathrm{CMV}$ transmission was added for seronegative mothers in order to educate them about CMV prevention for subsequent pregnancies.

\section{Sociodemographic data collection}

During the postpartum interview, women were administered a 10-item standardized questionnaire including: knowledge about CMV, knowledge of their CMV status, age, birthplace, age at immigration if foreign born, education level, family revenue, number of children, age of children, number of children who attended daycare, and employment type (See Additional file 1 for full questionnaire). CMV awareness was categorized as CMV aware if women reported awareness by answering yes to either of the following questions: 1) Do you know anything about cytomegalovirus? and 2) Do you know if you are protected against cytomegalovirus? Age was classified into three groups (18-30, 31-35, $\geq 36$ years old). Place of birth of mothers were classified as: Canada, United States of America, Caribbean, South America, Europe, Africa, and Asia. Age at immigration was divided into two groups: younger than 12 years old or older [30]. The three categories for family income $(\leq \$ 30,000, \$ 31-$ 99,000 , and $\geq \$ 100,000$ ) were based on Statistics Canada classifications [31]. Level of education was categorized into two groups of pre-university and university levels. Occupational exposure was specified as working in child daycare centers, or working in health care facilities, such as hospitals, medical clinics, and long term care institutions, regardless of credentials.

\section{Statistical analysis}

The association between maternal socio-demographic characteristics and CMV seronegative status and CMV awareness were assessed using odds ratios. Multivariable logistic regression was used to adjust for potential confounders identified on univariate analysis and from the literature, including maternal age, birth place, education 
level, income, number of children, and type of employment. The multivariable analysis was restricted to only those women with complete data on all variables assessed $(n=479)$. All statistical tests were two-sided, and significance was set at a $p<0.05$. The analysis was conducted using SAS statistical software, version 9.3 (SAS institute, Cary, NC).

\section{Results}

Between April and December 2012 (240 days), 2659 women delivered in the maternity ward of CHU Sainte Justine. Recruitment took place for 80 days during that period. Detailed census of delivered women was collected for a third (27 days between October and December 2012) of the study period, during which time 439 women delivered. Of these women, 314 women were eligible for the study (85 women were excluded as they did not have first trimester serum available, 35 had babies hospitalized in the neonatal intensive care unit, two were minors and three had linguistic barriers). One hundred and fifty-seven (50\%) of these eligible women were not approached for recruitment due to logistic reasons (women not available due to medical interventions, away from the room, busy with other healthcare worker). Of the 157 women approached, nine $(5.7 \%)$ refused to participate in the study, resulting in 148 recruited women during the 27-day period. In summary, during the entire 240-day study period, 505 women were successfully recruited over 80 recruitment days. Fourteen of the recruited women were excluded from the final analysis ( 2 blood samples had insufficient quantity for testing, three laboratory requests were non-conforming, and nine laboratory results were equivocal), leaving 491 study subjects. All of the recruited women completed the questionnaire.

Overall, $46 \%(n=225)$ of women were CMV seronegative. The risk of being CMV seronegative according to maternal socio-demographic characteristics is summarized in Table 1. In the unadjusted analysis, significant risk factors for CMV seronegative status included Canadian vs. foreign born women (OR 8.28, 95 \% CI 5.45-12.58), high or middle vs. low income (OR 8.13, 95 \% CI 4.46-14.85, OR $3.68,95 \%$ CI 2.10-6.47, respectively), having no children or one other child vs. two children or more (OR 2.08, $95 \%$ CI 1.25-3.47 and OR 2.02, 95 \% CI 1.18-3.44, respectively). Compared to those women who did not work outside the home, health care workers had a significantly increased risk of CMV seronegative status (OR 3.35, $95 \%$ CI 1.70-6.62) as did all other trades (OR 2.10, 95 \% CI $1.33-3.32$ ), with the exception of daycare workers (OR $1.73,95 \%$ CI 0.71-4.19). There was no significant effect of age on CMV serostatus. In the multivariate analysis, the only significant risk factors for seronegative status remained Canadian vs. foreign-born women (aOR 6.88, $95 \%$ CI 4.33-10.94), and high or middle vs. low family income (aOR 4.68, 95 \% CI 2.09-10.48 and aOR 3.05, $95 \%$ CI 1.54-6.04, respectively). Among foreign-born women, $41 \%$ were from Africa, $27 \%$ from South America or the Caribbean, $24 \%$ from Europe or the United States, and $8 \%$ from Asia. The highest proportion of CMV seronegative foreign-born women was from Europe and the United States (58 \%), while the lowest proportion was from Asia (12\%) (Fig. 1). Young age at immigration ( $\leq 12$ years old) was significantly associated with seronegative status (aOR 4.23, 95\%CI 1.28-13.96).

The association between maternal CMV awareness, and CMV serostatus and socio-demographic factors is summarized in Table 2. Overall, $85 \%$ of women $(n=415)$ were not aware of CMV infection. Among them, $42.4 \%$ $(n=176)$ were CMV susceptible. Significant risk factors for being CMV unaware included foreign vs. Canadian born women (OR 2.06, 95 \% CI 1.22-3.49), non-university vs. university educated (OR 2.43, $95 \%$ CI 1.37-4.32), low or middle vs. high income family (OR 5.18, $95 \%$ CI 2.10-12.81 and OR 2.01, $95 \%$ CI 1.18-3.40, respectively), and unemployment or employment in the daycare setting or others trades vs. in the health care setting (OR 64.9, 95 \% CI 18.1-232.9, OR $20.695 \%$ CI 4.3-96.9 and OR 12.7, 95 \% CI 6.6-24.6, respectively). There was no significant effect of age or having children on CMV awareness. In the multivariate analysis however, only employment status remained a significant predictor of CMV unawareness (aOR 85.6, 95 \% CI 17.3421.3, aOR 18.6, 95 \% CI 3.6-95.9 and aOR 16.1, 95 \% CI 7.9-33.9, for unemployed, daycare workers, and other trades, respectively).

\section{Discussion}

In this single center observational study from the cosmopolitan city of Montreal, Quebec, we identified a number of risk factors for CMV seronegative status and lack of CMV awareness among post-partum women. While overall CMV susceptibility among pregnant women from the same hospital has decreased from a reported $63.3 \%$ [25] in 1972 to $46 \%$ in the present study, Canadian born women continue to be at increased risk of CMV seronegative status when compared to foreign born. In that previous study, $73 \%$ of Canadian mothers were seronegative vs. $29 \%$ of Italian mothers, which is comparable to the current $66 \%$ susceptibility rate in Canadian born vs. $20 \%$ in foreign mothers in the present study. The overall decrease in the number of CMV seronegative pregnant women is likely related to the smaller proportion of Canadian born women, due to migratory trends in the province of Quebec since the end of the 1970s [29]. Family income was identified as another factor for CMV seronegative status, with women of higher family income at increased risk of CMV seronegative status. These findings were also compatible with the recent Australian study that 
Table 1 Maternal CMV serostatus according to socio-demographic characteristics:

\begin{tabular}{|c|c|c|c|c|c|c|c|}
\hline & Population & CMV negative & CMV positive & Crude OR (95 \% Cl) & $p$-value & Adjusted ORt (95 \% Cl) & $p$-value \\
\hline & $N$ (column \%) & $N($ row \%) & $N($ row \%) & & & $N=479$ & \\
\hline & $491(100)$ & $225(46)$ & $266(54)$ & & & & \\
\hline Age group & & & & & & & \\
\hline $18-30$ & $185(38)$ & $83(45)$ & $102(55)$ & 1.00 & & 0.95 & \\
\hline & & & & $(0.63-1.58)$ & 0.98 & $(0.51-1.76)$ & 0.87 \\
\hline $31-35$ & $186(38)$ & $88(47)$ & $98(53)$ & $1.10(0.69-1.74)$ & 0.69 & $0.69(0.39-1.23)$ & 0.21 \\
\hline$\geq 36$ & $120(24)$ & $54(45)$ & $66(55)$ & 1 & & 1 & \\
\hline Born in Canada & & & & & & & \\
\hline Yes & $272(55)$ & $182(67)$ & $90(33)$ & 8.28 & & 6.88 & \\
\hline & & & & $(5.45-12.58)$ & $<0.0001$ & $(4.33-10.94)$ & $<0.0001$ \\
\hline No & $219(45)$ & $43(20)$ & $176(80)$ & 1 & & 1 & \\
\hline Education level & & & & & & & \\
\hline Up to university & $188(38)$ & $76(40)$ & $112(60)$ & 1 & & 1 & \\
\hline University & $303(62)$ & $149(49)$ & $154(51)$ & 1.43 & 0.06 & 1.01 & 0.96 \\
\hline & & & & $(0.99-2.06)$ & & $(0.60-1.70)$ & \\
\hline Family income ${ }^{a}(N$ & & & & & & & \\
\hline Low & $101(21)$ & $19(19)$ & $82(81)$ & 1 & & 1 & \\
\hline Middle class & $228(48)$ & $105(46)$ & $123(54)$ & 3.68 & $<0.0001$ & 3.05 & 0.002 \\
\hline & & & & $(2.10-6.47)$ & & $(1.54-6.04)$ & \\
\hline High & $150(31)$ & $98(65)$ & $52(35)$ & 8.13 & $<0.0001$ & 4.68 & 0.0002 \\
\hline & & & & $(4.46-14.85)$ & & $(2.09-10.48)$ & \\
\hline Other children & & & & & & & \\
\hline 0 & $229(47)$ & $113(49)$ & $116(51)$ & 2.08 & 0.01 & 1.59 & 0.30 \\
\hline & & & & $(1.25-3.47)$ & & $(0.66-3.86)$ & \\
\hline 1 & $171(35)$ & $83(49)$ & $88(51)$ & 2.02 & 0.005 & 1.54 & 0.19 \\
\hline & & & & $(1.18-3.44)$ & & $(0.81-2.93)$ & \\
\hline$\geq 2$ & $91(18)$ & $29(32)$ & $62(68)$ & 1 & & 1 & \\
\hline Daycare & & & & & & & \\
\hline Yes & $218(44)$ & $93(43)$ & $125(57)$ & 1 & & 1 & \\
\hline No & $273(56)$ & $132(48)$ & $141(52)$ & 1.26 & 0.21 & 1.14 & 0.74 \\
\hline & & & & $(0.88-1.80)$ & & $(0.51-2.54)$ & \\
\hline Employment & & & & & & & \\
\hline None & $112(23)$ & $35(31)$ & $77(69)$ & 1 & & 1 & \\
\hline DCW & $25(5)$ & $11(44)$ & $14(56)$ & 1.73 & & 1.81 & \\
\hline & & & & $(0.71-4.19)$ & 0.23 & $(0.60-5.50)$ & 0.29 \\
\hline $\mathrm{HCW}$ & $53(11)$ & $32(60)$ & $21(40)$ & 3.35 & & 1.19 & \\
\hline & & & & $(1.70-6.62)$ & 0.0005 & $(0.47-3.03)$ & 0.71 \\
\hline Others & $301(61)$ & $147(49)$ & $154(51)$ & 2.10 & & 0.92 & \\
\hline & & & & $(1.33-3.32)$ & 0.002 & $(0.51-1.66)$ & 0.78 \\
\hline
\end{tabular}

${ }^{a}$ low $=\leq 30,000 \$ / y$, middle $=31-99,000 \$ / y$, high $=\geq 100,000 \$ / y$

t $\mathrm{OR}$ adjusted for all variables in the table

$D C W$ daycare worker, HCW health care worker

highlighted a marked socioeconomic gradient in CMV seroprevalence and its positive association with congenital CMV [32]. Our overall proportion of CMV seronegative pregnant women is similar to that reported in other wealthy countries such as Australia (43\%), France (48 \%), and United States (28-49 \%) [32]. 


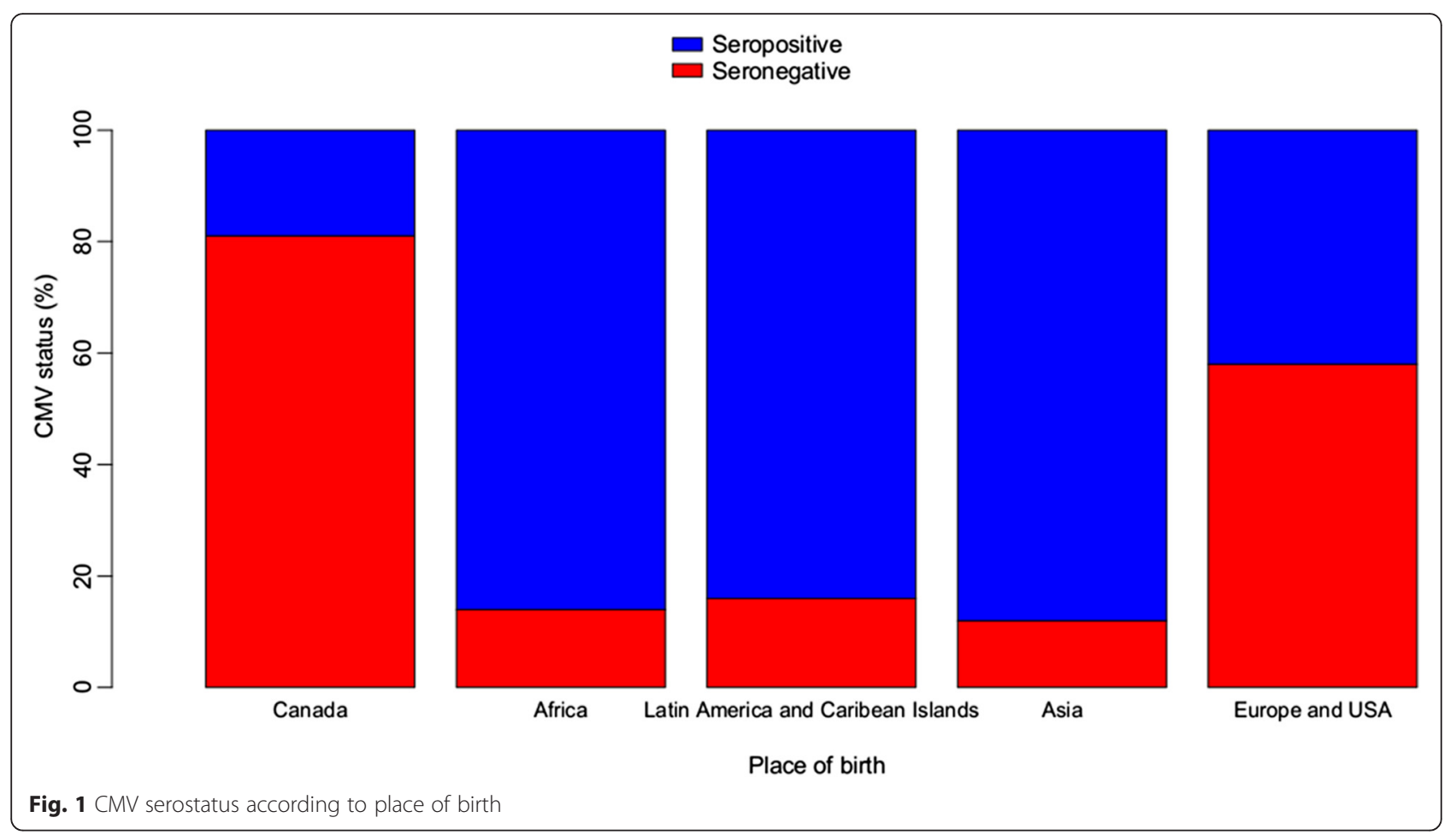

In contrast with previous studies [33, 34], risk factors that were not significant for seronegative status in the present study included age, level of education, number of children, and attendance at daycare. While this may in part be due to our relatively small sample size, we suspect that socio-demographic trends unique to Canada, and specifically to the province of Quebec, may provide further explanation.

Education level was not predictive of CMV susceptibility potentially because our population was highly educated (61 \% had a university degree) independently of the country of birth. In fact, Canada has the highest proportion $(64.1 \%)$ of adult population with post-secondary education among developed countries and the proportion of recent immigrants with a university degree is twice as high as among Canadian born fellows [35].

Family size and subsidized day care centers programs are also recent changes that might have influenced the epidemiology of CMV in the province of Quebec. Family size in Canada decreased from 3.7 in 1971 to 2.5, and even to 2.3 persons in Quebec, in 2011 [36]. With an increase in the number of subsidized child daycare programs across Canada, childcare spaces doubled from 1992 to 2004, of which 43 \% were in Quebec (although this province represents only $22 \%$ of the Canadian population) [36]. Among the 262 studied women who had children previously, $83 \%$ had children with day care exposure. These two risk factors were therefore too correlated to measure the independent effects from children exposure at home and their daycare attendance on maternal seronegative status.

Finally, we did not see an increased risk of seronegative status among daycare workers. While they were only 25 mothers in that category, their seronegativity rate was comparable to that of the whole cohort. This is similar to the result of a previous study of daycare workers in Montreal, where $43 \%$ were seronegative, although $69 \%$ were Canadian born [27]. Daycare workers in Toronto had a lower seronegativity rate $(33 \%)$ but those seronegative workers experienced a high rate of seroconversion (12.5\% in 1 year) [37].

Perhaps most concerning is that while $46 \%$ of mothers studied were seronegative and thus susceptible to primary infection during pregnancy, only $15 \%$ of mothers (and $22 \%$ of the seronegative ones) were aware of CMV. Even among healthcare workers, only $64 \%$ were aware of CMV in our study. This level of awareness about CMV was similar to the 14-25\% rate reported in United States [38, 39], and the $12.5 \%$ among Dutch pregnant women [40]. Interestingly, although CMV is the most common congenital infection, Dutch mothers seemed much more aware of other congenital infections like toxoplasmosis and listeriosis. Identifying women with a lack of CMV awareness is important so as to target appropriate public health interventions. Lack of knowledge may lead to more risky behaviors and increase risks of infection. It has been well demonstrated that seronegative mothers with a child less than 36 months of age attending daycare who already knew that they were 
Table 2 Maternal CMV awareness according to socio-demographic characteristics

\begin{tabular}{|c|c|c|c|c|c|c|c|}
\hline & Population & CMV aware & & Crude OR & $p$-value & Adjusted OR† & $p$-value \\
\hline & & Yes & No & & & (95 \% Cl) & \\
\hline & $N($ column \%) & $N($ row \%) & $N($ row \%) & & & $N=479$ & \\
\hline & $491(100)$ & $76(15)$ & $415(85)$ & & & & \\
\hline CMV status & & & & & & & \\
\hline CMV negative & $225(46)$ & $49(22)$ & $176(78)$ & & & & \\
\hline CMV positive & $266(54)$ & $27(10)$ & $239(90)$ & & & & \\
\hline Age group & & & & & & & \\
\hline $18-30$ & $185(38)$ & $18(10)$ & $167(90)$ & $1.64(0.81-3.29)$ & 0.17 & $1.79(0.74-4.32)$ & 0.20 \\
\hline $31-35$ & $186(38)$ & $40(22)$ & $146(78)$ & $0.64(0.35-1.19)$ & 0.16 & $0.81(0.39-1.69)$ & 0.58 \\
\hline$\geq 36$ & $120(24)$ & $18(15)$ & $102(85)$ & 1 & & 1 & \\
\hline Born in Canada & & & & & & & \\
\hline Yes & $272(55)$ & $53(19)$ & $219(81)$ & 1 & & 1 & \\
\hline No & $219(45)$ & $23(11)$ & $196(89)$ & $2.06(1.22-3.49)$ & $<0.01$ & $1.81(0.92-3.55)$ & 0.08 \\
\hline Education level & & & & & & & \\
\hline Up to university & $188(38)$ & $17(9)$ & $171(91)$ & $2.43(1.37-4.32)$ & $<0.003$ & $1.40(0.66-2.97)$ & 0.38 \\
\hline University & $303(62)$ & $59(19)$ & $244(81)$ & 1 & & 1 & \\
\hline Family income ${ }^{a}(N=$ & & & & & & & \\
\hline Low & $101(21)$ & $6(6)$ & $95(94)$ & $5.18(2.10-12.81)$ & $<0.001$ & $0.89(0.28-2.86)$ & 0.84 \\
\hline Middle class & $228(48)$ & $32(14)$ & $196(86)$ & $2.01(1.18-3.40)$ & $<0.01$ & $1.02(0.52-2.04)$ & 0.95 \\
\hline High & $150(31)$ & $37(25)$ & $113(75)$ & 1 & & 1 & \\
\hline Other children & & & & & & & \\
\hline 0 & $229(47)$ & $35(15)$ & $194(85)$ & 1 & & 1 & \\
\hline 1 & $171(35)$ & $32(19)$ & $139(81)$ & $0.78(0.46-1.33)$ & 0.36 & $0.88(0.27-2.88)$ & 0.93 \\
\hline$\geq 2$ & $91(18)$ & $9(10)$ & $82(90)$ & $1.64(0.76-3.57)$ & 0.21 & $2.67(0.63-11.41)$ & 0.18 \\
\hline Daycare & & & & & & & \\
\hline Yes & $218(44)$ & $35(16)$ & $183(84)$ & 1 & & 1 & \\
\hline No & $273(56)$ & $41(15)$ & $232(85)$ & $1.08(0.66-1.77)$ & 0.75 & $0.84(0.26-2.75)$ & 0.77 \\
\hline Employment & & & & & & & \\
\hline None & $112(23)$ & $3(3)$ & $109(97)$ & $64.9(18.1-232.9)$ & $<0.0001$ & $85.6(17.3-421.3)$ & $<0.0001$ \\
\hline Others & $301(61)$ & $37(12)$ & $264(88)$ & $12.7(6.6-24.6)$ & $<0.0001$ & $16.1(7.6-33.9)$ & $<0.0001$ \\
\hline DCW & $25(5)$ & $2(8)$ & $23(92)$ & $20.6(4.3-96.9)$ & 0.0001 & $18.6(3.6-95.9)$ & 0.0005 \\
\hline HCW & $53(11)$ & $34(64)$ & $19(36)$ & 1 & & 1 & \\
\hline
\end{tabular}

low $=\leq 30,000 \$ / y$, middle $=31-99,000 \$ / y$, high $=\geq 100,000 \$ / y$

† OR adjusted for all variables in the table except CMV status

$D C W$ daycare worker, HCW health care worker

pregnant were more motivated to alter behavior than mothers attempting pregnancy. In that study, counseling pregnant women was $85 \%$ effective in reducing risk of CMV acquisition [41]. Indeed, according to the 2002 statement of the American College of Obstetrics and Gynecology, the greatest impact to reduce CMV diseases is educating pregnant women about preventive measures [42]. Yet, less than half of US obstetricians had mentioned them to their patients in the 2008 National Survey [43]. Other than health care workers, most of our participants were unaware about CMV, even those working in high- risk setting such as the daycare. Given the few CMV aware women, our sample size may have been too small to discern that influence.

The limitations of the present study are that it was a single center study, which may not be representative of the larger Canadian population. While the proportion of foreign-born mothers in our population was representative of the metropolitan Montreal population [29] it does not reflect the rest of the province of Quebec, which has lower immigrant populations [44], or Western Canada, which counts immigrants mostly from Asia and India. 
Moreover, CHU Sainte-Justine is a francophone referral hospital, and thus mothers from the First Nations and the Asian continent (more likely to be English speaking) are likely underrepresented. Furthermore, the level of wealth of participants in our study is higher than that described in the general population of Canada, which may make it difficult to generalize our results. Finally, our sample size may have been too small to detect differences in the socio-demographic risk factors for CMV seronegative status and awareness, given the large number of explanatory variables per category. Larger, more representative population level studies are needed to identify more precisely these risk factors and target groups for anticipatory behavioral intervention.

\section{Conclusions}

In conclusion, in the present study, we identified a high proportion of CMV seronegative status and unawareness among pregnant women. Given that there is no current consensus on the role of CMV screening of pregnant women, primary prevention through education of at risk women about CMV transmission and basic hygiene preventive measures could potentially have a major public health impact. Moreover, increased education of health care workers, who themselves may lack CMV awareness, could help reinforce these education measures. In this respect, collaboration with other large mother-child centers in the province of Quebec and other provinces across Canada are needed to improve the reproducibility and generalizability of our findings and to develop public health interventions.

\section{Additional file}

Additional file 1: CMV questionnaire. (DOC $45 \mathrm{~kb}$ )

\section{Competing interests}

The authors declare that they have no competing interests.

\section{Authors' contributions}

$S W, V L, L C, B T$ developed the research protocol and the questionnaire about CMV knowledge and maternal socio-demographic characteristics. SW and LC collected the data in this study. All authors analyzed and interpreted the data, contributed to the editing of the manuscript and have reviewed and approved its final version.

\section{Acknowledgements}

The authors would like to thank participating women and the research assistant, Mrs. Adela Barbaros, who helped with data collection. This work was supported in part by grants from CLS Behring to the principal investigator. This work has been presented in part at the Infectious Diseases Society of America Annual Meeting, Oct 2-6 2013, San Francisco, California, Abstract 1782

\section{Author details}

${ }^{1}$ Infectious Disease Division, Department of Paediatrics, CHU Sainte Justine, Université de Montréal, 3175 Ch. de la Cote-Sainte-Catherine (bureau 7412), Montréal H3T1C5, QC, Canada. ${ }^{2}$ Department of Social and Preventive Medicine, Faculty of Medicine, Laval University, Pavillon Ferdinand-Vandry (bureau 4633), 1050 Av de la Medicine, Québec G1V0A6QC, Canada. ${ }^{3}$ Department of Microbiology, CHU Sainte-Justine, Université de Montréal, 3175 Ch. de la Cote-Sainte-Catherine (bureau 2901), Montréal H3T1C5, QC, Canada. ${ }^{4}$ Obstetric and Gynecology Department, CHU Sainte Justine, Université de Montréal, 3175 Ch. de la Cote-Sainte-Catherine (bureau 4822), Montréal H3T1C5, QC, Canada. ${ }^{5} 5632$ Irving Layton, Montréal H4W0A2, QC, Canada.

Received: 15 October 2015 Accepted: 11 March 2016

Published online: 15 March 2016

\section{References}

1. Kenneson A, Cannon MJ. Review and meta-analysis of the epidemiology of congenital cytomegalovirus (CMV) infection. Rev Med Virol. 2007;17(4):253-76.

2. Grosse SD, Ross DS, Dollard SC. Congenital cytomegalovirus (CMV) infection as a cause of permanent bilateral hearing loss: a quantitative assessment. J Clin Virol. 2008;41(2):57-62. Epub 2007/10/26.

3. Dollard SC, Grosse SD, Ross DS. New estimates of the prevalence of neurological and sensory sequelae and mortality associated with congenital cytomegalovirus infection. Rev Med Virol. 2007:17(5):355-63.

4. Yow MD, Demmler GJ. Congenital cytomegalovirus disease - 20 years is long enough. N Engl J Med. 1992;326(10):702-3.

5. Grosse SD, Ortega-Sanchez IR, Bialek SR, Dollard SC. The economic Impact of Congenital CMV Infection: Methods and Estimates In: Reddehase MJ, editor. Cytomegalovirus: from Molecular Pathogenesis to Intervention. Germany: Caister Academic Press; 2013: p49-55.

6. Lopez AS, Ortega-Sanchez IR, Bialek SR. Congenital Cytomegalovirus-related Hospitalizations in infants <1 Year of Age, United States, 1997-2009. PIDJ. 2014:33(11):1119-23.

7. Stagno S, Pass RF, Dworsky ME, Henderson RE, Moore EG, Walton PD, et al. Congenital cytomegalovirus infection: the relative importance of primary and recurrent maternal infection. NEJM. 1982;306(16):945-9.

8. Fowler KB, Stagno S, Pass RF, Britt WJ, Boll TJ, Alford CA. The outcome of congenital infection in relation to maternal antibody status. NEJM. 1992;326: 663-7.

9. Boppana SB, Rivera LB, Fowler KB, et al. Intrauterine transmission of cytomegalovirus to infants of women with preconceptional immunity. NEJM. 2001;344(18):1366-71.

10. Carlson A, Norwitz E, Stiller RJ. Cytomegalovirus infection in pregnancy: should all women be screened? Rev Obst Gynecol. 2010;3(4):172-9.

11. Walker S, Palma-Dias R, Wood EM, Shekleton P, Giles ML. Cytomeglaovirus in pregnancy: to screen or not to screen. BMC Pregnancy Childbirth. 2013;13:96

12. Boppana SB et al. Saliva polymerase-chain-reaction assay for cytomegalovirus screening in newborns. N Engl J Med. 2011;364(22):2111-8.

13. Oliver SE et al. Neurodevelopmental outcomes following ganciclovir therapy in symptomatic congenital cytomegalovirus infections involving the central nervous system. J Clin Virol. 2009;46 Suppl 4:\$22-6.

14. Kimberlin DW et al. Effect of ganciclovir therapy on hearing in symptomatic congenital cytomegalovirus disease involving the central nervous system: a randomized, controlled trial. J Pediatr. 2003;143(1):16-25.

15. Kimberlin DW et al. Pharmacokinetic and pharmacodynamic assessment of oral valganciclovir in the treatment of symptomatic congenital cytomegalovirus disease. J Infect Dis. 2008;197(6):836-45.

16. Kimberlin, D.W. Six months versus six weeks of oral valganciclovir for infants with symptomatic congenital cytomegalovirus (CMV) disease with and without central nervous system involvement: Results of a Phase III, randomized, doubleblind, placebo-controlled, multinational study.ID week, october 5, 2013.

17. Kimberlin et al. Valgancyclovir for symptomatic congenital cytomegalovirus. NEJM. 2015:372(10):933-43.

18. Manicklal S, Emery VC, Lazzarotto T, Boppana SB, Gupta RK. The "silent" global burden of congenital cytomegalovirus. Clin Microbiol Rev. 2013;26(1):86-102.

19. Adler SP, Finney JW, Manganello AM, Best AM. Prevention of child-to mother transmission of cytomegalovirus among pregnant women. J Pediatr. 2004;145:485-91.

20. Harvey J, Dennis CL. Hygiene interventions for prevention of cytomegalovirus infection among childbearing women: systematic review. J Adv Nurs. 2008; 63(5):440-50.

21. Vauloup-Fellous C, Picone O, Cordier AG, Parent-du-Chatelet I, Senat MN, Frydman R, Grangeot-Keros L: Does hygiene counseling have an impact on the rate of CMV primary infection during pregnancy? Results of a 3 year prospective study in a French Hospital. J Clin Virol. 2009;46 suppl 4:S 49-53. 
22. Embil JA et al. Prevalence of cytomegalovirus infection in a normal urban population in Nova Scotia. Can Med Assoc J. 1969;101(12):78-81.

23. Embil JA, Macdonald JM, Scott KE. Survey of a neonatal population for the prevalence of cytomegalovirus. Scand J Infect Dis. 1975;7(3):165-7.

24. Larke RP et al. Congenital cytomegalovirus infection in an urban Canadian community. J Infect Dis. 1980;142(5):647-53.

25. Montplaisir S, Martineau B. Infection caused by the cytomegalic virus (CMV) in the area of Montreal: an epidemiologic study. Can J Public Health. 1972; 63(4):333-41.

26. Preiksaitis JK, Larke RP, Froese GJ. Seroepidemiology of cytomegalovirus infection in the Northwest Territories of Canada. Arctic Med Res. 1988;47 Suppl 1:701-4.

27. Joseph SA et al. Risk factors for cytomegalovirus seropositivity in a population of day care educators in Montreal, Canada. Occup Med (Lond). 2005;55(7):564-7.

28. Vaudry W et al. Congenital cytomegalovirus infection in high-risk Canadian infants: Report of a pilot screening study. Can J Infect Dis Med Microbiol. 2010;21(1):e12-9.

29. Comeau M. Messier M, Lavoie S. Caracteristiques des mères de nouveauxnés à Montréal. L'evolution des naissances à Montréal, 1984-2009. Bibliothèque et Archives nationales du Quebec et Canada, 2011.

30. Stadler LP, Bernstein DI, Callahan ST, Turley CB, Munoz FM, Ferreira J, Achaya M, Simone AG, Patel SM, Edwards KM, Rosenthal SL. Seroprevalence and Risk Factors for Cytomegalovirus Infections in Adolescent Females. JPIDS. 2013:2(1):7-14.

31. Canada S. Income Statistics Division, Annual Income Estimates for Census Families and Individuals. 2014.

32. Basha J et al. Congenital cytomegalovirus infection is associated with high maternal socio-economic status and corresponding low maternal cytomegalovirus seropositivity. J Paediatr Child Health. 2014;50(5):368-72.

33. Stars SA et al. Seroprevalence of cytomegalovirus infection in the United States, 1988-1994. CID. 2006:43:1143-51.

34. Adler SP. Molecular epidemiology of cytomegalovirus: viral transmission among children attending a daycare center, their parents, and caretakers. J Pediatr. 1988;112(3):366-72.

35. Statistics Canada. Report of the Pan - Canadian Education Indicators Program. 2014.

36. Statistics Canada. Canadian Council on Social Development Stats and Facts, Report. 2012.

37. Ford-Jones EL, Kitai I, Davis L, Corey M, Farrell H, Petric M, et al. Cytomegalovirus infection in Toronto child-care centers: a prospective study of viral excretion in children and seroconversion among day-care providers. Pediatr Infect Dis J. 1996;15:507-14.

38. Ross DS et al. Women's knowledge of congenital cytomegalovirus: results from the 2005 HealthStyles survey. J Womens Health (Larchmt). 2008;17(5): $849-58$

39. Price SM, Bonilla E, Zador P, Levis DM, Kilgo CL, Cannon MJ. Educating women about congenital Cytomegalovirus: assessment of health education material through a web-based survey. BMC Womens Health. 2014;14:144.

40. Pereboom MT et al. Observational study to assess pregnant women's knowledge and behaviour to prevent toxoplasmosis, listeriosis and cytomegalovirus. BMC Pregnancy Childbirth. 2013;13:98.

41. Adler S, Finney J, Manganello AM, Best A. Prevention of child-to-mother transmission of cytomegalovirus among pregnant women. J Ped. 2004 145:485-91.

42. American College of Obstetrics and Gynecologists. ACOG practice bulletin. Perinatal viral and parasitic infections. Number 20, September 2000. Int J Gynaecol Obstet. 2002;76:95-107.

43. Centers for Disease Control and Prevention. Knowledge and practices of obstetricians and gynecologists regarding cytomegalovirus infection during pregnancy-United States, 2007. MMWR. 2008;57(3):65-8.

44. Statistic Canada. Proportion of foreign born population and population belonging to visible minority groups per metropolitan census area, 2006 and projection 2031. National Household Survey, July 2011, p8. www12.statcan.gc.ca.

\section{Submit your next manuscript to BioMed Central and we will help you at every step:}

- We accept pre-submission inquiries

- Our selector tool helps you to find the most relevant journal

- We provide round the clock customer support

- Convenient online submission

- Thorough peer review

- Inclusion in PubMed and all major indexing services

- Maximum visibility for your research

Submit your manuscript at www.biomedcentral.com/submit
Biomed Central 